\title{
O populismo na perspectiva de Ernesto Laclau: uma alternativa
}

\section{para a esquerda?}

Kamila Lima do Nascimento

\author{
Kamila Lima do Nascimento \\ Doutoranda em Ciência Política pela \\ Universidade Federal de Pelotas. \\ Pesquisadora visitante na Universidade \\ de Ottawa. \\ E-mail: kamiladonascimento@gmail.com
}

\begin{abstract}
Resumo
Este artigo tem como objetivos: 1) apresentar o conceito de populismo construído pelo teórico político argentino Ernesto Laclau; 2) analisar criticamente a defesa da aplicação, na prática, do populismo no campo político. A importante contribuição do autor constitui-se um grande avanço para a compreensão do fenômeno do populismo como uma lógica política dotada de racionalidade própria. Em contraste com a literatura tradicional, ele oferece uma visão afastada de preconceitos e interpreta o populismo como um modo de construção do povo, tal como qualquer outro. Ele não carrega qualquer conteúdo específico, seja de direita ou de esquerda, bom ou ruim, como tradicionalmente se acreditou. Não obstante, concordando com a construção teórica do autor, fomos levados a questionar sobre a desejabilidade do populismo no campo político considerando a sua natureza, baseada, especificamente, na construção hegemônica de um povo contra o poder. Nossa hipótese era de que a lógica populista é incompatível com a democracia. Isto porque, em vez de levar em conta o todo da comunidade, ele provoca uma divisão antagônica radical no social. Assim, não nos ocupamos em demonstrar que o trabalho de Laclau é um erro e que devemos voltar à visão tradicional, mas analisar se a lógica política populista deveria ser acolhida pela esquerda política considerando seu possível prejuízo à democracia.
\end{abstract}

\section{Palavras-chave}

Populismo. Ernesto Laclau. Teoria Política. Esquerda Política.

\begin{abstract}
This article aims to: 1) present the concept of populism built by the Argentine political theorist Ernesto Laclau; 2) to critically analyze the defense of the practical application of populism in the political field. The important contribution of the author constitutes a great advance for the understanding of the phenomenon of the populism as a political logic endowed with own rationality. In contrast to the traditional literature, he offers a perception away from judgements in which populism is taken as a way of construction of the people, such as any other. It does not carry any specific content, from the right or left wing, good or bad, as it was traditionally believed. Nevertheless, in agreement with the theoretical construction of the author, we were led to question over the desirability of populism in the political field considering its nature, based specifically on the hegemonic construction of a people against the power. Our hypothesis was that populist logic is incompatible with democracy. This is because, instead of considering the whole of the community, it causes a radical antagonistic split in the social. Thus, we are not concerned with demonstrating that Laclau's work is a mistake and that we must return to the traditional view but analyze whether populist political logic should be accepted by the political left considering its possible damage to democracy.
\end{abstract}

\section{Keywords}

Populism. Ernesto Laclau. Political Theory. Political Left. 
Kamila Lima do Nascimento

\section{Introdução}

A obra "A Razão Populista", publicada em 2005, de autoria do teórico político argentino Ernesto Laclau, provocou uma verdadeira reviravolta sobre o tema do populismo, estimulando novas produções entre os apoiadores e os críticos. O motivo é que a alternativa proposta pelo autor, apoiada nos preceitos pós-estruturalistas ${ }^{1}$, oferece uma nova perspectiva sobre o populismo que é radicalmente diferente da literatura tradicional sobre o assunto. Inclusive, perspectiva é uma palavra-chave aqui, pois Laclau não trabalha no sentido de contestar ou desprovar os conceitos de populismo existentes, mas de deslocar o lugar de sua análise: do lugar de onde o populismo se manifesta, a sua apresentação em diferentes lugares, ao populismo pensando como ser em si mesmo, como lógica.

Para o autor, as inúmeras más interpretações sobre o populismo, que colaboraram com a caracterização pejorativa do termo, não consideravam o fenômeno em si, mas apenas as suas manifestações e por isso o populismo tornou-se uma espécie de fantasma. Ele foi, por essa razão, "confinado ao domínio do impensável, a ser um simples contraponto de formas políticas dignificadas com status de plena racionalidade", o que se fez possível através da condenação ética na consideração dos movimentos populistas (LACLAU, 2013: p. 55). Para Laclau, seria necessário "resgatá-lo de sua posição marginal no interior do discurso das ciências sociais" para que possamos compreendê-lo (LACLAU, 2013: p. 55). Mas esse resgate não é uma tentativa para encontrar o verdadeiro referente ao populismo, mas fazer o oposto: mostrar como ele não possui uma unidade referencial e que é tão simplesmente uma forma de construir o político².

Como mostraremos a seguir, Laclau propõem pensar o populismo como uma lógica política que não dispõe de conteúdos específicos, mas possui uma natureza singular. Para ele, o populismo é uma lógica radical cuja principal característica é a divisão simbólica do social em dois campos antagônicos, separando o "povo" do seu "outro".

Nesse artigo, realizaremos uma análise crítica da formação populista como desenvolvida por Laclau. Entretanto, o problema que nos guiará não será o de saber se a lógica do autor está correta do ponto de vista teórico, mas o seguinte: considerando que sua lógica esteja correta, isto é, que o populismo seja uma lógica política que tem como característica fundamental a construção do povo contra o poder, seria justificável defender a sua aplicação na prática no campo político?

Nossa hipótese é de que a divisão radical do campo político que a lógica populista propõe é incompatível com a democracia, por isso indefensável. Como iremos demonstrar, o "outro", contra o qual a lógica populista se opõe, não é simplesmente uma categoria de poder, mas é um outro "povo". Desse modo, embora a formação populista se desenvolva no intuito de fazer a vontade do povo, que é um dos principais valores da democracia, ela perde a característica democrática ao defender o poder da parte em detrimento do todo.

Na teoria de Laclau, possivelmente por conta de sua influência marxista, o autor faz parecer que o povo do populismo luta contra o seu opressor, que seria uma instituição, um poder. Mas o que de fato ocorre no populismo é um choque extremo, e muitas vezes violento, de um povo contra o outro - uma divisão ideológica radical dentro de um mesmo povo, entre aqueles que ocupam contingentemente o poder e aqueles que se sentem dele excluídos. $O$ resultado desse choque é indeterminado. Podemos somente imaginar uma série de cenários entre dois extremos. De um lado, um cenário de inversão total da situação, em que os despossuídos tomarão o poder deixando o grupo anterior em sua condição prévia, por outro, uma oportunidade de inclusão total em que as desigualdades seriam canceladas. 
O importante, contudo, é dizer que na impossibilidade de poder prever o resultado desse possível choque, e sabendo-se que ele pode inclusive resultar em uma versão totalitária, parece-nos perigoso adotar uma posição de quase neutralidade e dizer que, sendo assim, tomada como uma lógica política, o populismo não deve ser dito como positivo ou negativo. Uma lógica política que não é por nada assegurada, que não possui qualquer conteúdo e nem se baseia em qualquer princípio não parece ser defensável.

O método que utilizaremos para testar nossa hipótese será o da análise do discurso. De um modo geral, as diferentes abordagens da análise do discurso possuem em comum o acolhimento da dimensão simbólica como parte das construções sociais e a consideração de que o discurso, resultado da prática discursiva, não se restringe a estrutura ordenada de palavras, mas é a expressão de um sujeito no mundo que explícita sua identidade (CHIZZOTTI, 2006). Logo, a proposta do analista do discurso é a construção de um dispositivo de interpretação. "Esse dispositivo tem como característica colocar o dito em relação ao não dito, o que o sujeito diz em um lugar com o que é dito em outro lugar, (...) procurando ouvir naquilo que o sujeito diz, aquilo que ele não diz mas que constitui igualmente o sentido de suas palavras" (ORLANDI, 2001: p. 59).

Procedimentalmente, o primeiro passo da pesquisa será a leitura do material conduzida de forma seletiva, retendo as partes essenciais para o desenvolvimento do estudo, procurando ver nele sua discursividade, desfazendo a ilusão de que o que foi dito só poderia ter sido dito daquele modo e a relação palavra-coisa. Em seguida, faremos a análise crítica do material procurando encontrar nele o dito do interdito do não dito e, em seguida executaremos a escrita do artigo.

Na primeira seção, apresentaremos o conceito de populismo enquanto categoria ontológica, diferenciando-o, de tal modo, de outros conceitos clássicos que possuem sentido ôntico. Na segunda parte, mostraremos o populismo como uma lógica política com racionalidade própria. A terceira seção trata de mostrar como ocorre uma formação populista e também como se forma o povo do populismo. Por fim, na última seção trataremos da crítica contra a lógica populista como alternativa para a esquerda, que do nosso ponto de vista se constitui em um posicionamento anti-democrático.

\section{O Populismo como um conceito ontológico}

Esta primeira seção será dedicada a esclarecer a especificidade do populismo, enquanto uma noção que possui sentido ontológico e, através deste esclarecimento, vamos diferenciá-la das noções clássicas desenvolvidas por diversos autores da ciência política. Consequentemente, marcaremos por que essa diferenciação é importante e em que a lógica desenvolvida por Ernesto Laclau inova e avança na compreensão do fenômeno do populismo.

A ontologia ${ }^{3}$ é um termo filosófico que se refere às características de um ser em si mesmo e enquanto ser, independente de sua manifestação. Dessa forma, o sentido ontológico do populismo é aquele que representa esta noção independentemente das formas como se manifesta na realidade empírica ou de como está normatizado, os seus sentidos mais fixos e imutáveis, aqueles que poderíamos considerar como constitutivos de seu ser.

Neste sentido, tratar do conceito de populismo em seu sentido ontológico significa afastar-se do tipo de análise amplamente praticada no campo tradicional da ciência política, que consiste em comparar diversas experiências populistas e traçar as suas similitudes para, em seguida, a partir dessas observações, proporem-lhe seu conceito. 
É o caso, por exemplo, do trabalho de Margaret Canovan (1981) que desenvolveu uma tipologia para o estudo do populismo que incluía tantos aspectos diferentes que a fez dividi-lo em duas categoriais - o populismo agrário e o populismo político - e, no entanto, ela mesma reconheceu que algumas características de uma categoria poderiam também ser encontradas na outra, o que resultou, segundo Laclau (2013), em ambiguidades do seu próprio trabalho. Ou, ainda, o caso de Donald MacRae (1969), que também não conseguiu resistir à tentação de atribuir ao populismo um conteúdo social particular. Ele criou uma descrição detalhada sobre o populismo que, em seguida, encontrou dificuldades para aplicá-la aos populismos realmente existentes, tendo que por fim aceitar que o populismo contemporâneo guardava pouco em comum com a sua descrição (LACLAU, 2013). Peter Wiles (1969) incorreu exatamente no mesmo erro, segundo Laclau (2013). Após desenvolver detalhadamente 0 conceito do populismo, incluindo uma soma de vinte e quatro características, teve de dedicar à segunda parte de seu livro à análise das exceções. Esta é, segundo o autor argentino, "uma característica geral da literatura sobre o populismo: quanto mais determinações são incluídas no conceito geral, menos este conceito é capaz de conferir hegemonia a análises concretas" (LACLAU, 2013: p. 41).

Segundo Laclau (2013: p. 52), a crítica contra esse tipo de abordagem poderia ser feita a partir de duas justificativas: 1 ) as formas que cada populismo pode adquirir são tão diversas que esse tipo de análise não pode ser proposta sem que as características "mais fundamentais" não venham também acompanhadas por uma série de exceções; 2) este tipo de intervenção apenas se refere a um "conteúdo social (interesses de classe ou outros interesses setoriais) que o populismo expressa, enquanto permanecemos no limbo em relação ao motivo pelo qual essa forma de expressão é necessária". Nas palavras do Ernesto Laclau:

A esta altura geralmente ficamos com as alternativas pouco palatáveis que já examinamos: ou restringir o populismo a uma de suas variantes históricas ou tentar uma definição geral, que sempre será muito limitada. Neste último caso, os autores normalmente voltam-se para o frustrante exercício a que nos reportamos acima: colocar sob a etiqueta de "populismo" uma série de movimentos muito díspares e, ao mesmo tempo, nada dizer sobre o sentido dessa etiquetagem (LACLAU, 2013: p. 52).

Logo, a pretensão de Laclau, ao propor um novo conceito de populismo, não era tomar cada uma das formas empíricas que o populismo assumiu ao logo do tempo para contrapor-se às análises anteriores e mostrar os seus enganos. Tendo em vista que a sua análise está centrada no campo ontológico, ele tratou de mostrar que as limitações que levaram o populismo a ser rechaçado eram, na verdade, um reflexo de pressupostos ontológicos limitados aos quais as análises anteriores se anexavam.

Não foi minha intenção encontrar o verdadeiro referente do populismo, mas fazer o oposto: mostrar como o populismo não possui uma unidade referencial, pois não está atribuído a um fenômeno delimitável, mas a uma lógica social, cujos efeitos perpassam muitos fenômenos. O populismo é, muito simplesmente. um modo de construir o político (LACLAU, 2013:28).

De acordo com o autor, os estudos atualmente disponíveis partem da ideia de que a função da política é a administração dos problemas sociais e que essa função é melhor praticada quanto maior for a racionalidade que substituirá progressivamente as decisões baseadas em interesses pessoais. Visto dessa perspectiva, o populismo aparece como irracional e indefinível e é assim "confinado ao domínio do impensável, a ser um simples oposto de formas políticas dignificadas com o status de plena 
racionalidade" (LACLAU, 2013:55). Dito de outra forma, partindo desse pressuposto, o populismo é apresentado como um contraponto degenerado da política racional que seria estável, duradoura e bem estabelecida, enquanto o primeiro seria transitório, vago e impreciso.

Uma forma possível de contrapor este tipo de análise seria dar uma diferente resposta para o populismo, mostrando exemplos de onde ele não aparece de modo tão vago, tão transitório ou tão impreciso. Entretanto, isso seria mais uma vez manter a discussão no nível ôntico ${ }^{4}$, o que sabemos que não era a intenção de Laclau. Ele propõe, ao contrário, manter todas as características relacionadas ao populismo, rejeitando, porém, os preconceitos que estão na base de sua desvalorização. Isto porque a vagueza, a transitoriedade e a imprecisão relacionada ao populismo apenas são características pejorativas na medida em que se contrapõe à ideia da política racional e madura, governada por alto grau de determinação institucional em que a imaturidade dos atores sociais seria suplantada num estágio posterior. Se tomarmos um ponto de partida diferente, neste caso o pós-estruturalismoe a teoria do discurso ${ }^{5}$, a vagueza e a imprecisão do populismo aparecem como consequências da própria realidade social que em algumas situações é vaga e indeterminada.

Para a teoria do discurso, as decisões políticas são tomadas através de disputas, nem sempre racionais e progressivas, e todas as construções hegemônicas são sempre parciais. Partindo dessa perspectiva, falar em uma forma política "transitória" seria uma tautologia, pois a dimensão de substituição e falência é própria da ação política e "desponta necessariamente - em diferentes graus em todos os discursos políticos, subvertendo e complicando a operação das assim chamadas ideologias 'mais maduras'", e não é apenas um fenômeno populista (LACLAU, 2013: p. 54). Também a ideia da irracionalidade não faz qualquer sentido sob a ótica pós-estruturalista, já que, para essa vertente, não existe qualquer possibilidade de haver uma política completamente racional e transparente. Com base nesses pressupostos, Laclau aparta o populismo dos preconceitos habitualmente atribuídos a ele e propõe que pensemos a sua noção como uma lógica política que possui uma racionalidade própria, em vez de uma lógica tosca e irracional.

O autor também recusa tratar o populismo enquanto movimento ou ideologia. Isto porque, visto enquanto movimento, o populismo aparece como uma espécie de expressão ou um tipo de mobilização de um grupo já constituído e a questão da sua construção é deixada de fora da análise. Para Laclau, ao contrário, os conteúdos que uma lógica populista pode mobilizar são sempre contingentes e impossíveis de se prever antecipadamente. Também o populismo não se liga a nenhuma orientação ideológica particular, e ele pode vir a ser tomado tanto pela esquerda quanto pela direita política. Isso ocorre porque os significantes que o populismo põe em funcionamento flutuam, ou seja, qualquer grupo ou movimento, seja ele de direita ou de esquerda, pode declarar-se representante dos interesses do povo.

(...) deve ter ficado claro, a esta altura, que por 'populismo' não entendemos um tipo de movimento, identificado ou com uma base social especial ou com uma orientação ideológica particular, mas o entendemos como uma lógica política. Todas as tentativas de localizar o que é idiossincrático no populismo em elementos como o pertencimento ao campesinato ou aos pequenos proprietários, ou na resistência à modernização econômica, ou na manipulação pelas elites marginalizadas são, como vimos, essencialmente equivocados: eles sempre serão ultrapassados por uma avalanche de exceções (LACLAU, 2013: p. 181). 
É "uma certa inflexão de seus temas que torna uma lógica como populista e não o caráter particular da ideologia ou da instituição" (LACLAU, 2013: p. 189). Portanto, o populismo possui uma forma determinada: ele é uma lógica política com racionalidade própria. Entretanto, os conteúdos que se ligam a ela são impossíveis de se predeterminar.

Em suma, o conceito de Laclau aparta-se da literatura do populismo que trata da sua manifestação - seu sentido ôntico - para abordar sua natureza constitutiva - seu sentido ontológico. Nossa crítica, na mesma forma, não irá buscar contestar os conteúdos manifestados nos exemplares do populismo já praticados - embora muito pudesse ser falado sobre isso. Também não queremos refutar o argumento do autor e sua análise. Nosso objetivo é, a partir da própria análise de Laclau, opor-se a ideia de que o populismo poderia ser uma alternativa defensável no campo político. Na próxima seção, mostraremos que características específicas, ou que inflexões fazem com que uma lógica política se configure como populista; logo, as suas características fundamentais, ontológicas.

\section{O Populismo como uma lógica política}

Nesta seção, explicitaremos as características específicas de uma leitura pós-estruturalista do populismo promovida por Ernesto Laclau. Como estamos tratando de uma noção que possui sentido ontológico, esses atributos referem-se ao ser independente de sua manifestação; logo, independente de quaisquer conteúdos sociais ou ideológicos que apresente.

Em primeiro lugar, o populismo é considerado por Laclau como uma lógica política que tem como racionalidade própria a simplificação do espaço político e a divisão simbólica do social em dois campos antagônicos separando o "povo" de seu "outro". A lógica política está ligada ao momento da ruptura do tecido social. Ela possui um caráter antiinstitucional e surge como um desafio à ordem vigente e como uma tentativa de estabelecer uma nova ordem no lugar desta.

Assim, as práticas populistas emergem do fracasso da política e das instituições sociais. Ela "é a linguagem da política quando não pode haver política, como de costume: um modo de identificação característico de períodos de contingência e desalinhamento, envolvendo o redesenho radical das fronteiras sociais" (PANIZZA, 2005: p. 9). Sua especificidade é a representação do povo contra um poder que lhe é negado, que the exclui e que, portanto, deve ser derrotado com o intuito a dar lugar ao verdadeiro povo: "A dimensão anti status quo é essencial para o populismo, já que a completa constituição das identidades populares exige a derrota política do outro que é considerado como opressor ou explorador do povo e, portanto, impede a sua completude" (PANIZZA, 2005: p. 3).

O populismo pode emergir a partir de diversas circunstâncias. Dentre as mais comuns estão: 1 ) o colapso da ordem social e da perda de confiança na capacidade do sistema político para restaurá-lo. As crises econômicas são típicas destas situações; 2) o esgotamento das tradições políticas e o descrédito dos partidos políticos que podem advir, por exemplo, de alegações de corrupção, malversação, entre outros. Nesses casos, o populismo assume a forma de a "política de anti-política"; 3) alterações ao nível da economia, da cultura e da sociedade, tais como processos de urbanização e modernização econômica, mudanças no perfil demográfico e no equilíbrio entre as classes sociais; 4) representações políticas fora das instituições políticas tradicionais. $\mathrm{O}$ surgimento do rádio como uma forma de comunicação de massa, por exemplo, que foi associada com a primeira onda de líderes populistas na América Latina (PANIZZA, 2005).

Apesar dessa variedade de situações, o que a lógica do populismo põe em xeque em todas essas circunstâncias é a questão da representação do povo. O "discurso político populista apela para a 
crença de que, de alguma maneira, as promessas democráticas para 'o povo' foram sabotadas por 'interesses especiais'", logo, que seus interesses soberanos não foram devidamente representados (LAYCOCK, 2005: p. 173). O populismo visa corrigir os problemas políticos a partir da verdadeira representação do povo contra o poder que lhe foi negado. As batalhas políticas populistas visam transformar "as divisões que constituem as identidades populistas e estabelecer novas fronteiras políticas. Estas batalhas são contra o 'outro' do povo que impede as identidades populares de alcançar a plenitude" (PANIZZA, 2005: p. 17). Todo discurso populista é dirigido contra os inimigos do povo e, logo, sempre envolve uma dimensão antagônica radical. Dessa forma, "o populismo surge como o resultado de uma crise de representação, como uma resposta a incapacidade ou a recusa das elites em responder às preocupações do povo" (ARDITI, 2005: p. 80).

Aqui caberia a indagação: quais são os reais interesses do povo? Quanto à questão, é preciso começar por esclarecer que o povo e o outro, desta perspectiva, não são categorias sociológicas, mas "construções políticas, simbolicamente constituídas por meio da relação de antagonismo" (PANIZZA, 2005: p. 3). Dessa forma, o outro do povo é seu antagônico, aquele contra o qual ele luta, porque impede a sua realização. Contudo, nem o povo e nem o seu outro estão definidos antecipadamente. 0 que sabemos sobre eles é que a tarefa de encarnar o povo do populismo sempre será tomada por aqueles que foram excluídos do poder e o seu outro será formado por aqueles que negam aos primeiros o seu espaço e, por isso, são antagonizados.

O conteúdo específico de um determinado apelo populista varia de acordo com as diferentes formas que essa relação antagônica o definir. O "outro", em oposição ao "povo" pode ser apresentado em termos políticos ou econômicos ou como uma combinação de ambos, significando "a oligarquia", "os políticos", um grupo étnico ou religioso dominante, os "Washington insiders", "a plutocracia" ou qualquer outro grupo que impede o povo de alcançar a sua plenitude (PANIZZA, 2005: p. 4).

O tema da constituição do povo é absolutamente fundamental nas discussões sobre o populismo e a sua definição está longe de ser ponto pacífico. Ele já foi adjetivado como lascivo e virtuoso, irracional e realizador dos verdadeiros valores da nação, e também como uma ameaça à democracia ou titulares da soberania. Visões controvertidas e, muitas vezes, mutuamente contraditórias do povo que, no entanto, determinam, segundo Panizza (2005: p. 16), o terreno em que as batalhas políticas populistas são travadas.

Margaret Canovan (2005: p. 65), se debruçou sobre essa problemática. De acordo com ela, a definição teórica do povo sempre teve dois sentidos aparentemente incompatíveis. Ele significa ao mesmo tempo o todo da política e também uma parte da população, frequentemente aqueles excluídos da política. Para Arditi (2005: p. 82), a imprecisão quanto à definição do povo é uma imprecisão deliberada: "Ela permite borrar os contornos do 'povo' suficientemente para abranger qualquer pessoa com um agravo estruturado em torno de uma percepção de exclusão".

Para Laclau (2013), o povo é retroativamente nominado como o resultado de uma construção discursiva hegemônica. Sua ambiguidade no populismo é ainda mais profunda. O povo do populismo, segundo ele, não é apenas ora parte e ora todo, ele é a parte que é o todo. A imprecisão de seus contornos não é simplesmente deliberada com a finalidade de abranger um maior número de adeptos, mas uma consequência da operação da representação performativa que o cria.

O povo do populismo é a plebs que reivindica ser o único populus legítimo. Existe, nesse caso, uma parte que se identifica com o todo, logo o "povo" não é o todo mas, na verdade, é "algo menor que 
a totalidade: é um componente parcial que, ainda assim, aspira ser concebido como a única totalidade legítima" (LACLAU, 2013: p. 134). É uma parcialidade que quer funcionar como totalidade da comunidade.

O demos atribui a si mesmo, como algo que the cabe de direito, uma igualdade que pertence a todos os cidadãos. Ao agir assim, esta parte, que não é o todo, identifica sua propriedade imprópria com o princípio exclusivo de comunidade e identifica seu nome - o nome da massa indistinta de homens sem posição - com o nome da própria comunidade. (...). O povo se apropria da qualidade comum como se fosse sua. Estritamente falando, o que ele aporta à comunidade é a disputa (LACLAU, 2013: p. 151).

O povo, segundo Laclau (2013), não possui um conteúdo social dado; ele é uma construção radical, que constitui os agentes sociais enquanto tais e não expressa uma unidade do grupo previamente dada. Isso não significa que ele não tenha significado algum, mas apenas que este é construído retroativamente, porque ele é um o objeto do investimento hegemônico ${ }^{6}$.

É preciso destacar, no entanto, que quando falamos em um objeto do investimento hegemônico, não estamos nos referindo a uma segunda opção em relação à coisa verdadeira. Para Laclau, a plebs não é um falso do povo em relação ao verdadeiro povo como totalidade. A objetivação parcial, ou podemos dizer a representação, não é "um nível secundário refletindo uma realidade social primária constituída em outro lugar; [ela é], pelo contrário, o terreno primário dentro do qual o social é constituído" (LACLAU, 2005: p. 49). Dessa forma, a representação do povo pela plebs é a única possibilidade e não uma mera alternativa, já que a plenitude - 0 acesso imediato - é uma impossibilidade?.

Se o povo é um objeto retroativamente construído, logo, podemos dizer que o populismo nomeia retroativamente o objeto que promete defender. Isso mostra, segundo Reyes, por que "todas as tentativas de esclarecer ou capturar a essência do conceito de populismo são inúteis: o populismo é a dimensão do político que constrói e dá sentido ao povo" (REYES, 2005: p. 106). Na próxima seção, falaremos de como essa operação de nomeação retroativa é construída e logo como se forma uma lógica populista a partir de Laclau.

\section{A Formação populista}

Segundo Laclau (2013), há três precondições para que se possa considerar uma formação como populista: 1) é preciso haver uma articulação equivalente das demandas, que possibilite a emergência do "povo"; 2) a formação de uma fronteira antagônica interna separando o "povo" e o "poder"; 3) a unificação dessas várias demandas numa cadeia de equivalências. Apresentaremos cada uma dessas precondições a seguir.

Comecemos pela primeira. Laclau afirma que o populismo pressupõe uma articulação equivalente de demandas que possibilite a emergência do "povo". Como ela ocorre? O autor oferece um exemplo, que embora hipotético, corresponde, segundo ele, a uma situação amplamente vivenciada em países do Terceiro Mundo, que representa o processo de construção da lógica populista através da articulação de demandas insatisfeitas. 
Imagine-se uma grande massa de migrantes agrários que vão morar nas favelas das periferias de uma cidade industrial em desenvolvimento. Surgem problemas habitacionais e as pessoas por eles afetadas solicitam algum tipo de solução às autoridades locais. Aqui temos uma demanda que inicialmente talvez seja apenas uma solicitação. Se a demanda for atendida, o problema termina aí. Caso contrário, as pessoas podem começar a perceber que seus vizinhos têm outras demandas que também não foram atendidas: problemas com a água, a saúde, a escola etc. Caso a situação permaneça imutável durante algum tempo, ocorrerá um acúmulo de demandas não atendidas e uma crescente inabilidade do sistema institucional em absorvê-las de modo diferenciado (cada uma delas isolada das outras). Estabelece-se entre elas uma relação de equivalência. O resultado, caso a situação não seja contornada por fatores externos, poderia facilmente ser um abismo cada vez maior a separar o sistema institucional das pessoas (LACLAU, 2013: p. 123).

Em primeiro lugar, temos que destacar que, no exemplo do autor, estamos diante de uma situação de falta. Sem essa demanda inicial, não haveria possibilidade de uma articulação e nem a possibilidade para que uma lógica populista pudesse surgir. Há problemas sociais que estão afetando determinadas pessoas que demandam que tais problemas sejam resolvidos. Inicialmente, elas surgem como solicitações e assim permanecerão caso sejam atendidas de forma institucional. Se, de outro modo, forem negadas ou ignoradas pela institucionalidade, elas poderão ter o seu status modificado e se transformarem em exigências.

Dessa forma, as demandas podem tomar diferentes direções de acordo com a resposta dada a elas ou à sua relação com as demais demandas de outros demandantes. São três os possíveis destinos de uma demanda: 1) pode ser atendida (diferencialmente) pelo sistema e, nesse caso, participará da lógica institucional (lógica da diferença); 2) pode não ser atendida e permanecer isolada e; 3) pode não ser atendida e se articular, constituindo-se em um dos elos de uma cadeia de equivalências que expressará uma formação populista.

Nos dois primeiros casos, tratam-se das demandas que Laclau chama de demandas democráticas. $\mathrm{O}$ que existe de particularmente democrático nelas? De acordo com o autor, elas são assim chamadas não por se referirem a qualquer coisa relacionada ao regime democrático, mas porque guardam duas características comuns com o conceito usual de democracia que são: "(1) que estas demandas são formuladas para o sistema por alguém que foi excluído dele - que existe uma dimensão igualitária implícita nelas; (2) que sua emergência pressupõe algum tipo de exclusão ou privação" (LACLAU, 2013: p. 191). Dito de outro modo, as demandas democráticas são assim denominadas, porque foram excluídas dentro de um quadro institucional que prevê a sua inclusão igualitária, portanto, democrática.
A qualificação 'democrática' - que, na verdade, não é uma qualificação, pois repete como se fosse um adjetivo aquilo que já incluímos no conceito de demanda - aponta para o contexto discursivo/equivalencial, que é a condição da emergência da demanda, ao passo que os qualificativos 'pontual' ou 'isolado'" não o fazem (LACLAU, 2013: p. 194).

As demandas democráticas que foram atendidas participarão, como dissemos, da lógica institucional. Já aquelas que não forem atendidas, e também não se ligarem a uma lógica populista, ficarão dispersas no campo da discursividade. Elas são aquelas cujas particularidades se chocam com as 
particularidades das demais demandas não atendidas e, por isso, a lógica da equivalência não consegue absorvê-las. Elas são radicalmente heterogêneas e diversificadas e, por estarem dispersas, podem sofrer as pressões estruturais dos discursos hegemônicos diferentes e rivais para articularem-se. Trata-se de um tipo de exclusão radical em que nenhuma relação é possível. Já as demandas que vierem estabelecer uma relação de equivalência são denominadas, por Laclau, de demandas populares. É a partir destas últimas que uma lógica populista pode emergir.

A formação da lógica equivalencial necessária para a emergência do populismo ocorre exatamente como a operação hegemônica desenvolvida por Laclau em sua teoria do discurso. Diante da inabilidade do sistema político para responder às solicitações, ocorrerá um acúmulo de demandas e a possibilidade de identificação entre os vários demandantes que podem perceber que compartilham em comum a experiência de negação do sistema, ou a experiência da falta.

Entre as várias demandas, uma demanda individual por um conjunto de razões circunstanciais adquire certa centralidade e passa a exercer o papel de representar as outras demandas como uma demanda universal contra o sistema: "Por um lado, ela continua sendo uma demanda particular; por outro lado, sua própria particularidade passa a significar algo muito diferente de si mesma: a totalidade da cadeia das demandas de equivalência" (LACLAU, 2013: p. 153). Para que as demandas permaneçam unidas elas precisam ser condensadas em torno de um nome.

O populismo possui como particularidade a representação do povo contra o poder, isso significa que o nome do povo será necessariamente aquele que irá nomear a cadeia de equivalências como um denominador comum ou significante vazio ${ }^{8}$. Ele é o nome que tem por função consolidar o vago sentimento de solidariedade entre as demandas da cadeia de equivalências. O nome do povo "exercerá uma irresistível atração sobre qualquer demanda vivida como algo insatisfeito e, como tal, como algo excessivo e heterogêneo ante a estrutura simbólica existente" (LACLAU, 2013: p. 170). Logo, "o que era simplesmente uma mediação entre demandas agora adquire consistência própria" (LACLAU, 2013: p. 150).

Esse povo não é um objeto específico e pode ser representado por vários nomes. Como a articulação de demandas ocorre antes que um nome lhe seja adicionado, isso significa que a nomeação é, como dissemos, uma produção retroativa. Logo, não existe o povo antes de sua própria objetivação e, portanto, o nome do povo não nomeia algo que já existia, pois ele é politicamente constituído.

Laclau utiliza a construção retroativa do povo em oposição a qualquer concepção transcendental e também para afastar a ideia de que o povo seria racionalmente constituído. Dessa perspectiva, ele aparta o populismo de sua ideia de irracionalidade dando uma explicação plausível e bastante refinada para seu surgimento. Deslocando a ideia do aparecimento do populismo do líder político para os próprios excluídos e suas demandas ele destaca o aspecto de luta política em contraste com a concepção de massas manipuladas. Embora muito possa se dizer sobre isso - por exemplo, destacar que as duas coisas podem ocorrer concomitantemente, ou seja, uma situação de falta e um trabalho político de um grupo para as articular - nosso argumento na seção seguinte não se dará no sentido de questionar a construção teórica de Laclau, mas de dizer que partindo dela o populismo ainda assim não é nem defensável e nem desejável.

\section{Populismo: uma política radical para a esquerda?}

A discussão intelectual promovida por Ernesto Laclau nos coloca diante de uma questão um tanto controversa, que é a defesa - por parte especialmente de esquerda política - da aplicação na 
prática do populismo no campo político. Defesa, talvez, seja uma palavra forte. A maior parte dos autores que embarcaram na inovação teórica de Laclau - e mesmo o próprio autor - tratam o populismo como uma possibilidade entre as demais, uma alternativa que não deve ser receada. Nossa perspectiva, em contraste, é de que o populismo, como uma prática política, deve ser afastado. Não se trata de um comprometimento crítico contra a teoria do autor argentino. O populismo, como proposto nas páginas anteriores, é um avanço teórico importante para a compreensão do fenômeno - talvez a mais apropriada já produzida - e não há, de nossa parte, discordância contra ela. Pelo contrário, é ao concordar com o autor mencionado que iremos questionar a defesa do populismo como uma prática política desejável.

De acordo com o que foi apresentado antes, o populismo possui um caráter antiinstitucional radical, em que o povo constrói a sua identidade contra o poder. Ele trata do momento em que o povo toma o poder contra as instituições que lhes oprime e é visto como o verdadeiro momento do povo em que sua vontade prevalece. A ruptura radical contra o poder também tem sido o objetivo principal da esquerda política, o que explica em parte a sua simpatia em relação ao populismo. Entretanto, há algumas considerações que devem ser feitas antes de nos rendermos à lógica populista.

Primeiramente, como dissemos, o populismo pode ser tomado tanto pela esquerda quanto pela direita, e na verdade isso pode ser facilmente comprovado pelos exemplos já experimentados na prática política de diferentes países do mundo. Isso quer dizer que a virada populista pode se dar em uma direção radicalmente progressista ou radicalmente conservadora, e não há qualquer garantia a priori sobre essa direção.

Em segundo lugar, como também afirma Laclau, o povo do populismo não é o todo, mas uma parte que toma a representação do todo contra o "outro"; logo, a proposta do populismo é de um choque entre povos, cada um promovendo-se como o verdadeiro. Além do mais, como também foi mostrado, essa parte do todo não é conhecida, pois o povo não existe antes de sua objetivação e é uma operação retroativa de nomeação. Portanto, não é possível antever quem seria o "povo" do populismo e que tipo de política seria colocada em funcionamento por ele. Poderia se tratar de um povo radicalmente igualitário ou racista e baseado em crenças de pureza moral, ou em grupos nacionalistas, entre outros.

Em terceiro lugar, o populismo tomado por Laclau é considerado como uma lógica política, como algo que não pode ser dito nem positivo e nem negativo, visto que ela é somente uma lógica, uma espécie de ferramenta, e a sua positividade ou negatividade vai depender, como dissemos, daqueles que a fizeram funcionar.

O problema, nesse caso, é que se não podemos determinar qualquer conteúdo ou direção em relação ao populismo, não temos razão para acreditar que ele seria um aliado e não um inimigo dos intentos da esquerda ou do "povo". Além disso, quando passamos da categoria do populismo para a defesa das práticas populistas, saímos do campo da abstração - em que ela é apenas um ideal abstrato e "vazio", imune das considerações éticas e morais - e entramos no campo da política, onde considerações de valor podem e devem ser feitas. Essas, por sua vez, não tomam por base uma construção ideacional, o que o populismo poderia ser, mas os exemplos de populismo que as nossas sociedades já testaram e em que obtiveram resultados bastante diferentes, estes sim, podendo ser avaliados do ponto de vista moral e ético, e que variam desde experiências igualitárias até situações totalitárias.

Ao apartar o campo ôntico do ontológico, analisando o populismo apenas na sua constituição, Laclau estabelece um distanciamento entre a lógica e a prática populista, como se a primeira tivesse sido mal analisada no passado, sendo por isso criticada, e que agora poderia ser vista de um ângulo diferente. Porém, olhar um objeto por uma perspectiva nova não leva necessariamente a mudanças em sua manifestação. A nova onda de defesa do populismo, por parte dos autores esquerdistas, parece 
desconsiderar os seus possíveis efeitos, como se ele fosse algo novo. Porém, a perspectiva oferecida por Laclau no campo teórico não invalida as experiências do passado e nem garante que novas práticas melhores - sejam realizadas.

Um quarto ponto, talvez o mais importante de nossa perspectiva, é que a divisão política em dois campos antagônicos que o populismo realiza é, segundo pensamos, uma postura anti-democrática e incompatível com nossa sociedade atual. Nos dias de hoje, mais do que em qualquer momento da nossa história, temos consciência da complexidade das relações sociais e de como ela funciona de maneira orgânica e que as partes não podem ser divididas sem prejuízo para o todo.

Desde que o imaginário democrático tornou-se predominante na nossa sociedade ocidental a defesa de um grupo ou classe contra outra passou a ser insustentável. A democracia não divide, mas junta. A condenação que faz é contra os privilégios de determinados grupos e não contra os grupos em si. Do mesmo modo, não defende ou se coloca do lado de um grupo, pois isto também seria um modo de privilegiamento. Assim, não é possível ser a favor da ascensão de uma parte da comunidade contra outra, se entendemos que a democracia é o governo de todos.

Convém destacar que o posicionamento de oposição ao populismo - como o que abertamente assumimos neste texto - seria considerado, com base nos escritos de Mouffe $^{9}$ (2017: p. 17), como parte do establishment, ou seja, uma posição dos que estão no poder e que, segundo a autora, bombardeiam os defensores do populismo "com declarações alarmistas que clamam que o populismo tem que ser eliminado, porque significa uma ameaça mortal para a democracia".

De nossa parte, pensamos ser absolutamente possível ser ao mesmo tempo parte da esquerda e fora do establishment e, ainda assim, ser um alarmista contra o populismo enquanto prática política desejável. Nossa posição não se trata de negar que mudanças são extremamente necessárias e urgentes, mas apenas dizer que o populismo não é um caminho apropriado para tais mudanças. Também não se trata de proferir que a construção teórica de Laclau incorre em erro, pelo contrário, de nossa parte acreditamos ser talvez o melhor desenvolvimento sobre o tema e o que melhor explica 0 fenômeno do populismo. Porém, não como uma categoria teórica, mas como um fenômeno político, ele deve ser rejeitado.

O que pensamos em relação ao populismo é que se não podemos ter qualquer controle sobre o mecanismo que promovemos, não deveríamos promovê-lo em primeiro lugar. Dizer que não devemos temer o populismo porque ele nada mais é que uma ferramenta, uma lógica que pode ser tomada por qualquer grupo, é o mesmo argumento daqueles que defendem a liberação das armas afirmando que armas não matam pessoas, são as pessoas que fazem isso.

Poderíamos inferir com Mouffe (2017) que o argumento que apresentamos é parte da histeria antipopulista que deve ser enfrentada "examinando o que esteve em jogo na emergência dos movimentos chamados 'populistas' nos últimos anos na Europa" (MOUFFE, 2017: p. 17). De nossa parte, acreditamos que em vez de tentar justificar o populismo como remédio contra o problema da falta de democracia devemos, em contraste, aplicar a democracia em doses mais altas.

Interessante notar quanto a isso, que o próprio Laclau em parceria com Chantal Mouffe, já havia construído em outra obra uma alternativa para a esquerda que os autores nomearam de Democracia Radical e Plural ${ }^{10}$. Em contraste com o populismo, o modelo de democracia construído por eles, não tinha por função articular demandas de grupos excluídos contra o poder institucional, mas demandas de grupos subordinados que estão em situação de marginalidade em relação ao poder e devem ter as suas 
pautas incluídas. Isso significa que a Democracia Radical e Plural trabalha no artifício da inclusão. Consiste na ampliação da pluralidade de espaços de debate e na expansão das fronteiras políticas de modo que os grupos subordinados possam ter as suas lutas politicamente reconhecidas como formas de opressão. A expansão das fronteiras é em si uma operação antiinstitucional, no sentido de que modifica as estruturas existentes, mas o que se intenta é incluir dentro do sistema aquelas identidades que antes não eram reconhecidas como legítimas.

Isto nos permite ver em que sentido podemos falar do projeto de uma democracia radical como alternativa para a esquerda. Este não pode consistir na afirmação, a partir de posições de marginalidade, de uma série de demandas anti-sistêmicas; ao contrário, ele deve se basear na busca de um ponto de equilíbrio entre um máximo avanço da revolução democrática numa ampla gama de esferas, e a capacidade de direção hegemônica e reconstrução positiva destas esferas, por parte dos grupos subordinados (LACLAU \& MOUFFE, 2015: p. 279). Grifo nosso

No caso do populismo, o que está em jogo é a fundação de um novo poder. Não se trata de deslocar as fronteiras de dentro do poder, mas em última análise destruir o poder para que outro diferente possa ser estabelecido. No populismo as demandas não são articuladas em uma totalidade, pois o espaço político único passa a ser dividido em dois campos. Trata-se da divisão radical entre o "povo" e o poder que é insensível a eles. Nesse caso, há uma articulação de demandas de grupos excluídos que tiveram o seu lugar negado dentro do poder.

O populismo, como o próprio Laclau admite, pode assumir formas totalitárias. A Democracia Radical e Plural, em contraste, é uma inflexão, uma recusa em oferecer um projeto de resolução final para os problemas sociais. Embora ela também possa ser tomada tanto pela esquerda quanto pela direita, ela precisa se comprometer sempre com o equilíbrio entre a expansão das diferenças e a articulação da diversidade em torno de um senso comum democrático.

Percebe-se pelo contraste das duas lógicas do mesmo autor, que há o aumento da radicalidade entre os dois modelos. Uma possível explicação é que a via democrática depois de alguns séculos, não parece surtir os mesmos efeitos revolucionários que Laclau e Mouffe tentaram radicalizar em seu primeiro modelo. Esse fato tem deixado a esquerda política mais inquieta. As mudanças parecem não ocorrer na mesma velocidade e os regimes democráticos, muitas vezes, tem tomado a direção de um conformismo de centro e da redução dos antagonismos na política. A preocupação da esquerda quanto a isso é a perpetuação de uma pequena aristocracia no poder, que governa para os seus próprios interesses e contra a vontade do povo, ou a impossibilidade da mudança por conta do consenso.

O populismo pareceria ser apropriado para o caso de que o consenso criado seja contrário à vontade do povo, que teria a oportunidade a partir desta lógica de tomar de volta o que é seu. Porém, como dissemos, não há nenhuma garantia de que de fato esse objetivo poderia ser alcançado. Além disso, sabemos que o que o povo - enquanto parte - acredita ser seu, não lhe pertence de fato, pois ele requer a tomada do todo.

Como já esclarecemos antes, qualquer conteúdo político do "povo", independente de que povo seja, só pode ser fruto de ideias de grupos específicos, todos se apresentando como portadores da verdadeira voz do povo. Também dissemos que o "outro" - que é pensado como um ininigo que, em última análise, deve ser destruído a fim de que a vontade do povo se torne real - também representase a si mesmo como o verdadeiro povo e não há maneira racional de decidir quem possui a verdade, pois a própria verdade é contingente e não racional. 
Assim, o "outro", contra o qual as batalhas do populismo são travadas, não são meras instituições de concreto ou um poder invisível, nem somente um discurso político, como defende Laclau. O outro é também o povo. Logo, o que temos é a divisão do povo em dois grupos políticos, cada qual declarando-se como o verdadeiro povo. Não existe qualquer grupo que se declare não povo, fora do povo ou diferente do povo. Alguns grupos podem acusar os outros de serem as elites, o poder dominante e etc., mas essa é a denominação de um grupo contra outro e nunca uma autodenominação.

A solução do populismo parece uma atitude radical quando a esquerda não consegue mais enxergar que eleições periódicas possam, enfim, mudar a realidade social, transformando igualdade abstrata em igualdade material. Porém, com o populismo corremos o risco não apenas de não alcançar a igualdade material, mas de regredir para regimes em que as diferenças são canceladas e a possibilidade da igualdade se torne mais remota, assim como pode afastar a possibilidade de alternância promovendo um poder que pode requerer manter-se eternamente.

Isto posto, com base em todas as razões apresentadas antes, defendemos como alternativa a radicalização da democracia. Entendemos a democracia como o governo de todos e que se baseia nos princípios da liberdade e da igualdade. Nesse sistema, as diferentes visões de mundo são reconhecidas, mas só podem se confrontar enquanto adversários dentro de uma arena com regras estabelecidas. Assim, se assumirmos a posição em defesa da democracia, devemos escapar das alternativas extremistas, refutando tanto o consenso e a neutralidade quanto a defesa de antagonismos políticos radicais que levam à exclusão.

É importante notar que a identificação do povo com uma parte da comunidade, geralmente identificada como os pobres, foi pensada principalmente por autores clássicos que tomavam por base modelos antigos de democracia. Contudo, uma importante mudança em relação a isso aconteceu na modernidade: a democracia deixou de ser considerada um governo de muitos e passou a ser vista como o governo de todos. Em contraste com o modelo antigo, "a democracia moderna, não tem limites, e é por isso que Spinoza a chama de 'absoluto'. Este movimento de muitos para todos é uma pequena mudança semântica, mas com consequências extraordinariamente radicais!" (HARDT e NEGRI, 2004: p. 240).

Na percepção moderna da democracia, a consideração de quem se identifica como povo é secundária em relação à consideração de que o sistema democrático não exclui a ninguém por ser um sistema de todos. É verdade que as revoluções modernas não instituíram imediatamente o conceito universal de democracia em termos práticos. Um exemplo disso foi a exclusão de certos grupos do direito ao voto, tais como as mulheres, os não proprietários, os não brancos, entre outros. No entanto, a noção do voto universal serviu para orientar os nossos desejos e práticas políticas e, até hoje, são fundamentais para respaldar o problema da exclusão (HARDT e NEGRI, 2004).

Nesse sentido a democracia, ao estabelecer o princípio do todo absoluto e do universal, não supõe a anulação automática de toda a exclusão na prática, todavia, oferece um imaginário igualitário em que todas as formas de exclusão podem ser contestadas. Desse modo, em contraste com o populismo, a luta democrática nunca pressupõe a divisão, mas sempre a inclusão no todo.

É importante destacar que a democracia não possui uma conceituação final. Mesmo os princípios considerados democráticos podem ser infinitamente reinterpretados, dependendo do contexto e dos objetivos de seus intérpretes. Sendo assim, a democracia está sempre aberta a entendimentos que flutuam de acordo com os sentidos que cada grupo político deseja imprimir.

Nossa própria definição é de que a democracia deve ser tomada como um sistema político complexo e que se deve se constituir a partir de quatro princípios fundamentais: a liberdade, entendida 
como a capacidade de ação dentro das relações de poder; a igualdade, pensada como um reconhecimento social da humanidade comum a todas as pessoas; a fraternidade, entendida como vínculo político e afetivo entre todos os seres humanos; e o governo de todos, que deve ser interpretado como o direito de todas as pessoas a participarem de decisões políticas.

É a partir dessas considerações que devemos nos mover em direção a um mundo mais inclusivo e contra todas as formas de dominação. Esse deve ser, segundo recomendamos, o caminho da nossa política contemporânea tanto para a esquerda como para a direita. É preciso ter em conta que no cenário político atual, onde todos estão interligados, a defesa de desenvolvimentos separados perdeu completamente o sentido e a justificação. Isso não significa um retorno ao pensamento de centro ou a tentativa de eliminar o dissenso. Nosso compromisso deve ser, considerando a existência de consensos e dissensos, da igualdade e da pluralidade, pensar em estruturas políticas que possam lidar com todos esses elementos em conjunto sem cair novamente na tentação da simplificação da complexidade através da exclusão.

\section{Considerações Finais}

Nesse artigo tratamos de apresentar o conceito do populismo na perspectiva de Ernesto Laclau e questionar a sua defesa na prática política. Resumidamente, o populismo nesta perspectiva é uma lógica política radical de deslocamento que envolve: 1) a divisão do campo social em dois; 2) a formação de um povo contra o poder e 3) a cristalização dos sentidos em torno de um nome que representará a completude ausente do social através da identificação com o nome do povo. Sem contestar o avanço teórico da construção do populismo na perspectiva do autor e mesmo concordando com ela, optamos por nos engajarmos contra a defesa de sua aplicação na prática argumentando que sua ausência de garantias representa um grande perigo para o seu emprego, e que a divisão do campo político em dois representa um retrocesso frente ao reconhecimento da complexidade social e da garantia da igualdade universal contra os privilégios dos grupos constituindo-se de modo anti-democrático. Nossa sugestão foi de que a esquerda política deve avançar em busca de uma democracia mais radical acolhendo o pensamento do todo e deixando de lado uma posição de grupo ou classe política.

(Recebido para publicação em janeiro de 2018)

(Reapresentado em abril de 2018)

(Aprovado para publicação em junho de 2018)

\section{Cite este artigo}

NASCIMENTO, Kamila Lima. O Populismo na Perspectiva de Ernesto Laclau: uma Alternativa para à Esquerda? Revista Estudos Políticos: a publicação semestral do Laboratório de Estudos Hum(e)anos (UFF). Rio de Janeiro, Vol. 9 | N.1, pp. 32 
- 48, julho de 2018. Disponível em: http://revistaestudospoliticos.com/

\section{Notas}

1. O pós-estruturalismo é uma vertente teórica comprometida com a contingência e que se opõe ao estruturalismo. Historicamente, os autores pósestruturalistas se identificam com as lutas da esquerda política contra a exclusão e em defesa do pluralismo e da igualdade.

2. O político aqui é considerado no sentido radical do ser ou essência da política em sua dimensão ontológica.

3. A noção de ontologia utilizada por Laclau baseia-se na obra de Martin Heidegger.

4. O nível ôntico está ligado a manifestação do ser do mundo, de acordo com a teoria de Martin Heidegger de onde Laclau extrai sua explicação.

5. Teoria do discurso é o nome dado ao desenvolvimento teórico desenvolvido por Ernesto Laclau.

6. O termo é usado em referência à teoria do discurso de Ernesto Laclau em que um discurso particular, de forma precária e contingente, toda a tarefa de representar um universal, hegemonizando-se.

7. Laclau aqui baseia-se no princípio Lacaniano da impossibilidade de acesso ao Real.

8. Na teoria de Laclau o significante vazio é aquele que não possui um sentido fixo, mas que cumpre a função de representar uma impossibilidade.

9. Chantal Mouffe escreveu junto com Ernesto Laclau a obra Hegemonia e Estratégia Socialista, considerada a obra principal do autor, além de ter colaborado em diversas outras pesquisas com ele.

10. O modelo radical e plural de democracia foi desenvolvido por Laclau e Mouffe em 1985, vinte anos antes da lógica populista. Nossa interpretação é de que ambas as lógicas possuem um sentido bastante diferente porém, em 2010, Laclau declarou, na revista Eurozine, que o populismo e a democracia radical coincidiam inteiramente.

\section{Bibliografia}


ARDITI, Benjamin. "Populism as an Internal Periphery of Democratic Politics". In: PANIZZA, Francesco, (ed.) Populism and the Mirror of Democracy. Phronesis. Verso Books, London, UK, 2005, pp.72-98.

CANOVAN, Margaret. Populism. Londres: Junction Books. 1981

. The People. Cambridge: Polity Press. 2005

LACLAU, Ernesto. "Populism: What's in a Name?" In: PANIZZA, Francesco, (ed.) Populism and the Mirror of Democracy. Phronesis. Verso Books, London, UK, 2005, pp. 32-49.

.The defender of contingency. Interviewed by Athena Avgitidou and Eleni Koukou. In: Eurozine, 2010. Disponível em: http://www.eurozine.com/articles/201002-02-laclau-en.html.

\section{3.}

A Razão Populista. São Paulo: Três Estrelas,

; MOUFFE, Chantal. LACLAU, Ernesto. Hegemonia e Estratégia Socialista: por uma política democrática radical. Rio de Janeiro: Intermeios, 2015.

LAYCOCK, David. "Populism and the New Right in English Canada". In: PANIZZA, Francesco, (ed.) Populism and the Mirror of Democracy. Phronesis. Verso Books, London, UK, 2005, pp. 172-201.

MAC RAE, Donald. "Populism as an Ideology". In: Ionescu e Gellner (orgs.). Populism. 1969, p.153-165

MOUFFE, Chantal. "The 'End of Politics' and the Challenge of Right-wing Populism". In: PANIZZA, Francesco, (ed.) Populism and the Mirror of Democracy. Phronesis. Verso Books, London, UK, 2005, pp. 50-71.

MOUFFE, Chantal. "O desafio Populista". Revista do Instituto Humanitas Unisinos, 2017, n.508, ano xvii, pp. 18-23.

PANIZZA, Francisco. "Introduction: populism and the mirror of democracy". In: PANIZZA, Francesco, (ed.) Populism and the Mirror of Democracy. Phronesis. Verso Books, London, UK, 2005, pp. 1-31.

WILES, Peter. "A Syndrome, not a Doctrine: Some Elementary Theses on Populism". in lonescu and Gellner (orgs.). Populism. 1969, p. 166-179.

REYES, Oscar. "Skinhead Conservatism: A Failed Populist Project". In: PANIZZA, Francesco, (ed.) Populism and the Mirror of Democracy. Phronesis. Verso Books, London, UK, 2005, pp. 99-117. 
O POPULISMO NA PERSPECTIVA DE ERNESTO LACLAU: UMA ALTERNATIVA PARA A ESQUERDA?

Kamila Lima do Nascimento 